\title{
Comparative Pre-Emptive Analgesic Efficacy Study of Novel Antiepileptic Agents Lamotrigine and Topiramate in Patients Undergoing Major Surgeries at a Tertiary Care Hospital: A Randomized Double Blind Clinical Trial
}

\author{
Ankush Gupta $^{\mathrm{a}}$ Uma A. Bhosale ${ }^{\mathrm{a}}$ Priyank Shah ${ }^{\mathrm{a}}$ Radha Yegnanarayan ${ }^{\mathrm{a}}$ \\ Shalini Sardesai ${ }^{b}$ \\ ${ }^{a}$ Department of Pharmacology and ${ }^{b}$ Department of Anesthesia, Smt. Kashibai Navale Medical College and General \\ Hospital, Narhe (Ambegaon), Pune, India
}

\section{Key Words}

Aldrete's score · Facial Rating Scale · Behavioral Rating

Scale $\cdot$ Visual Analog Scale $\cdot$ Pre-emptive analgesia

\begin{abstract}
Background: Central nervous sensitization, following surgical injury, leads to postoperative pain hypersensitivity due to lowered pain threshold in peripheral nociceptors and increased excitability of spinal neurons. Pre-emptive analgesia is intended to decrease pain perception and overall analgesic need by use of drug regimen, seizing CNS sensitization before exposure to painful stimuli. Few studies support preemptive analgesic efficacy of novel antiepileptic agent Gabapentin. Though Topiramate and Lamotrigine have been proven analgesic in animal models of chronic pain and clinical studies of Gabapentin-resistant neuropathic pain, literature search revealed scarce data on its pre-emptive analgesic efficacy. Purpose: This study is designed to study and compare the pre-emptive analgesic efficacy of Lamotrigine, Topiramate, and Diclofenac sodium in postoperative pain control. Methods: This randomized clinical trial included 90 patients of either sex, between 18 and 70 years undergoing major surgeries. Patients were randomly allocated to control
\end{abstract}

\section{KARGER}

E-Mail karger@karger.com

www.karger.com/aon and test groups and received respective treatment $30 \mathrm{~min}$ before induction of anesthesia. Aldrete's and pain scores were recorded using the Visual Analog Scale, Facial and Behavioral Rating Scale at awakening and at 1, 2, 4, 6, and $24 \mathrm{~h}$. Postoperative rescue analgesic consumption for $24 \mathrm{~h}$ was recorded. Results: Significantly higher pain scores were observed in the Topiramate group postoperatively for $2 \mathrm{~h}$ on all pain scales $(p<0.05)$, whereas in the control group it was significantly higher at $1 \mathrm{~h}(\mathrm{p}<0.05)$. Lamotrigine-treated patients were more comfortable throughout the study with significantly less $(p<0.05)$ postoperative analgesic requirement. Conclusions: Study results strongly suggest the preemptive analgesic efficacy of a single oral dose of Lamotrigine over Diclofenac and Topiramate in postoperative pain control.

(c) 2016 S. Karger AG, Basel

\section{Introduction}

Acute postoperative pain is a complex physiological reaction upon the damage of the tissue; noteworthy and detrimental since it can increase the patient's discomfort and may get transformed into chronic pain due to sensi- 
Fig. 1. Transition of acute pain to chronic

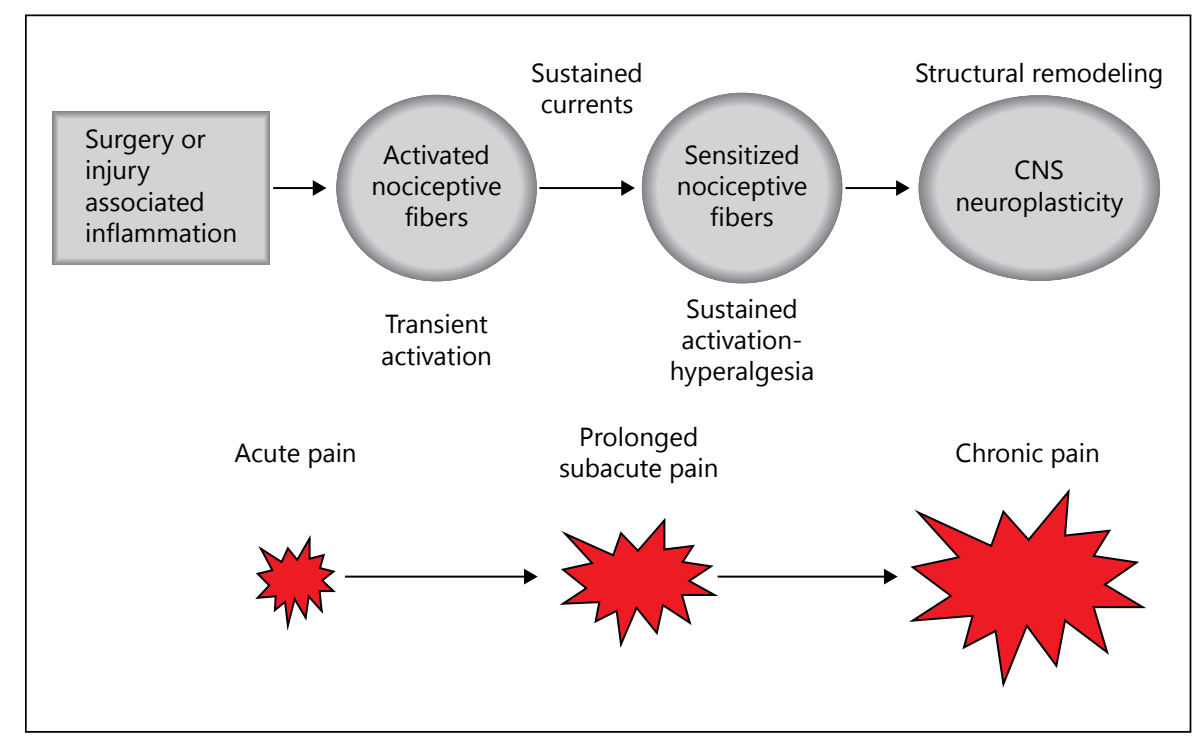
pain [3].

tization of the peripheral and central pain pathways (fig. 1) $[1,2]$.

Pre-emptive analgesia is an antinociceptive treatment that starts before surgery and prevents establishment of altered processing of afferent input following incisional and inflammatory injuries, which amplifies postoperative pain [4].

Earlier studies have demonstrated the importance of the pre-emptive effect of some drugs such as opioids, local anaesthetics, injectable general anaesthetics, and cyclooxygenase inhibitors in postoperative pain management [5-7]. Surgical procedures, even skin incisions, may result in this initial sensitization. These observations on the genesis and perception of pain led to the concept that analgesia administered before an initial noxious stimulus may be more effective than the same dose given later [2, 5].

Pre-emptive analgesic efficacy of Gabapentin has been demonstrated in earlier studies [8-10]. Topiramate and Lamotrigine had demonstrated analgesic effects in animal models of neuropathic pain including painful diabetic neuropathy and Gabapentin-resistant neuropathic pain, respectively. They have also been reported to be effective in several forms of neuropathic pain in clinical studies [11, 12].

This class of drugs works via 3 major mechanisms, that is, potentiation of GABA transmission, reduction of glutamate-mediated excitatory transmission, and blockade of voltage-activated ion channels. The later mechanism of action, in particular, is responsible for the success of the newer generation of antiepileptic drugs such as Lamotrig- ine, Gabapentin, and Topiramate, which have all been shown to be effective in animal models of neuropathic pain [11]. These novel antiepileptic agents share the same mechanism for their efficacy in neuropathic pain; unlike Gabapentin, pre-emptive analgesic efficacy of Topiramate and Lamotrigine has not been extensively studied and our experience about these drugs in acute postoperative pain management is still limited.

Our literature review showed that there were no adequate previous studies to compare the pre-emptive analgesic effect of novel antiepileptics such as Lamotrigine and Topiramate with established pre-emptive analgesic such as Diclofenac sodium in patients who underwent major surgeries. Hence, we designed this study to assess and compare the pre-emptive analgesic efficacy of oral Topiramate $200 \mathrm{mg}$ and Lamotrigine $100 \mathrm{mg}$ with oral Diclofenac sodium $100 \mathrm{mg}$ in patients eligible for surgery under spinal anesthesia.

\section{Methods}

A randomized, double blind, clinical trial with 3 parallel arm study groups design was used. In this single dose pharmacodynamics study, 90 post-operative cases of either sex between 18 and 70 years; those operated under spinal anesthesia in surgical departments such as orthopedic/obstetrics-gynecology and surgery were included. Sample size was calculated by using OpenEpi statistical software expecting a mean difference of pain score on Visual Ana$\log$ Scale (VAS) of 2 and SD of 2 at an $\alpha$-error of $5 \%$, power of 80 , and a 1:1:1 ratio between test, control, and placebo groups, the minimum required sample size was $28: 28: 28$, rounded up to 30 patients in each group. 


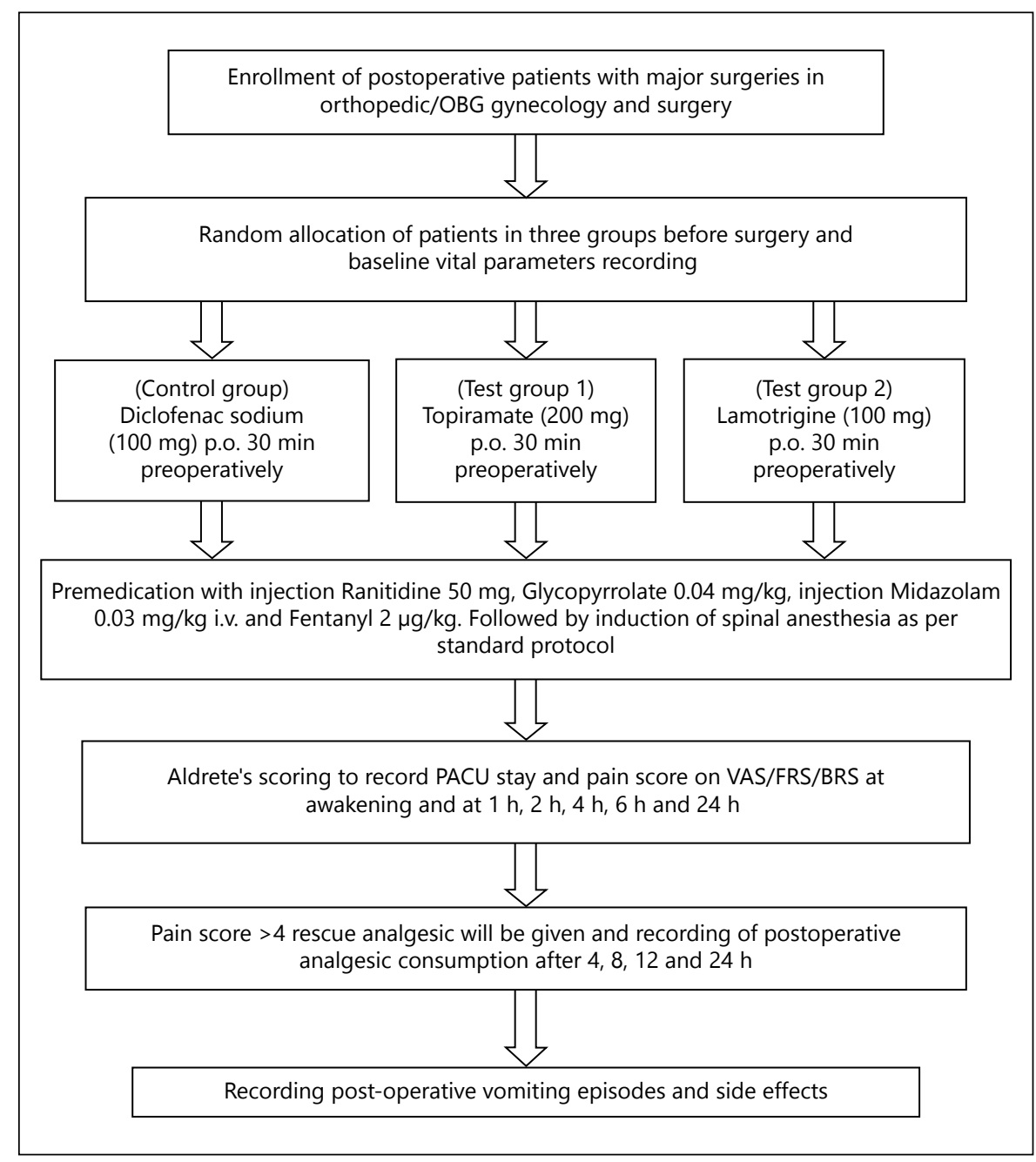

Fig. 2. Study flow chart.

Patients with diabetes, IHD, stroke, malignancy, psychiatric diseases, pregnancy-lactation, and ASA III and IV patients were excluded. After getting approval from the Institutional Ethics Committee (Ref. SKNMC No/Ethics/App/228/2014) and written informed consent, the patients were randomly assigned to one of the study groups. Randomization was done with the help of OpenEpi software version 2.3. This study was performed in accordance with the Declaration of Helsinki.

Premedication with injection Ranitidine $50 \mathrm{mg}$, Glycopyrrolate $0.04 \mathrm{mg} / \mathrm{kg}$, injection Midazolam $0.03 \mathrm{mg} / \mathrm{kg}$, and Fentanyl $2 \mu \mathrm{g} / \mathrm{kg}$ IV was followed by spinal anesthesia, carried out in the right lateral position, with $26 \mathrm{G}$ Quencke needle at L3-L4 inter space, by a standard technique. After free flow of cerebrospinal fluid from each patient after standard procedure of spinal anesthesia, patients received $3 \mathrm{ml}$ ( $15 \mathrm{mg}$ ) of $0.5 \%$, hyperbaric Bupivacaine. The respective drug, that is, Diclofenac $100 \mathrm{mg}$ control group, Topiramate $200 \mathrm{mg}$ (test group 1) and Lamotrigine 100 mg (test group 2) was given orally by one investigator $30 \mathrm{~min}$ prior to the induction of anesthesia and follow-up was done at awakening and at $1,2,4,6$, and $24 \mathrm{~h}$ by another investigator who was blinded. The baseline and postoperative periodic, that is (1,
2, 4, and $6 \mathrm{~h}$ ), vital parameters such as pulse rate, systolic blood pressure, diastolic blood pressure, $\mathrm{SpO}_{2}$ of all the patients were recorded. Postoperative level of analgesia was noted on VAS [13], Facial Rating Scale (FRS), and Behavioral Rating Scale (BRS) [14] at awakening and at $1,2,4,6$, and $24 \mathrm{~h}$; when pain score noted was $>4$ on the VAS $[13,15]$, rescue analgesic Diclofenac 50-100 $\mathrm{mg}$ was given and postoperative analgesic consumption for $24 \mathrm{~h}$ was recorded. Maximum dose of Diclofenac was limited to 300 $\mathrm{mg}$ in $24 \mathrm{~h}$. Duration of Postoperative Anesthesia Care Unit (PACU) stay was recorded by using modified Aldrete's scoring system; patients with a score $>9$ were shifted to the ward [16]. Postoperative vomiting episodes and side effects were also recorded (fig. 2).

\section{Statistical Analysis}

The data was analyzed using analysis of variance followed by Posthoc-Turkey statistical test, Student's t test was used for comparison of the means of continuous variables and normally distributed data and Mann-Whitney $U$ test (non-parametric test) using OpenEpi (version 2.3) and SciStatCalc (version 1.3) software, respectively. $\mathrm{p}<0.05$ was considered significant. 
Table 1. Baseline demographic profile of the patients undergoing surgeries

\begin{tabular}{lccc}
\hline Characteristics $(\mathrm{n}=90)$ & $\begin{array}{l}\text { Control group } \\
\text { (Diclofenac } 100 \mathrm{mg})\end{array}$ & $\begin{array}{l}\text { Test group 1 } \\
\text { (Topiramate 200 mg) }\end{array}$ & $\begin{array}{c}\text { Test group 2 } \\
\text { (Lamotrigine 100 mg) }\end{array}$ \\
\hline Age, years, mean \pm SD & $50.0 \pm 16.8$ & $48.6 \pm 12.6$ & $48.9 \pm 15.6$ \\
Sex, male:female & $20: 10$ & $16: 14$ & $18: 12$ \\
Surgery performed, $\mathrm{n}$ & & & \\
$\quad$ Inguinal hernioplasty & 12 & 10 & 11 \\
Inguinal hernia repair & 5 & 4 & 2 \\
Hydrocele repair & 3 & 3 & 1 \\
Open appendicectomy & 1 & 4 & 8 \\
Orthopedic surgeries & 4 & 6 & 3 \\
LSCS & 1 & 1 & 3 \\
Hysterectomy & 4 & $22.8 \pm 2.8$ & $24.4 \pm 1.4$ \\
BMI, kg/m ${ }^{2}$ mean \pm SD & $23.3 \pm 5.3$ & & $75.4 \pm 3.2$ \\
Vital parameters, mean \pm SD & & $72.9 \pm 1$ & $125.4 \pm 4.8$ \\
Pulse rate & $72.9 \pm 1.4$ & $121.8 \pm 2$ & $80 \pm 0.8$ \\
SBP, mm Hg & $121.8 \pm 2.4$ & $81.8 \pm 2$ & $95.1 \pm 1.6$ \\
DBP, mm Hg & $81.4 \pm 1.9$ & $95.1 \pm 2$ & $16 \pm 0.4$ \\
MAP, mm Hg & $94.8 \pm 1.9$ & $16 \pm 0.4$ & $99 \pm 0.6$ \\
Respiratory rate & $16 \pm 0.6$ & $99 \pm 0.7$ & \\
SpO, \% & $99 \pm 0.4$ & & \\
\hline
\end{tabular}

$\mathrm{BMI}=$ Body mass index; SBP = systolic blood pressure; DBP = diastolic blood pressure; MAP = mean arterial pressure; LSCS = lower segment caesarean section.

\section{Results}

In this randomized, double blind, clinical study, we assessed and compared the pre-emptive analgesic efficacy of Topiramate $(200 \mathrm{mg}$ ) and Lamotrigine $(100 \mathrm{mg})$ single oral dose on postoperative pain management. The demographic profiles of these patients were also studied and are presented in table 1 . There were 54 males and 36 females (mean age 49.2 years) enrolled in this study. Effect of preemptive analgesia on postoperative vital parameters showed no significant difference among the groups, presented in table 2.

The results of this study revealed the noteworthy preemptive analgesic efficacy of Lamotrigine in postoperative pain management. The significantly higher pain score was observed in the Topiramate group on all the 3 scales at $1 \mathrm{~h}$ and further till $2 \mathrm{~h}(\mathrm{p}<0.05)$ compared to Lamotrigine, while it was recorded significantly higher on VAS and BRS for $1 \mathrm{~h}(\mathrm{p}<0.05)$ compared to the control group. Pain scores among Lamotrigine and control groups were comparable except on VAS till $4 \mathrm{~h}$ and FRS at $2 \mathrm{~h}$, which were found to be significantly high $(\mathrm{p}<0.05)$ in the control group (table 3 ). Control and test group patients were more or less comfortable during the study; however, Lamotrigine group patients were more com- fortable throughout the study as observed with pain scales and adverse effects in $24 \mathrm{~h}$ (table 3). Analgesic requirement was significantly more in the Topiramate and control groups compared to the Lamotrigine group ( $\mathrm{p}<$ 0.05 ), whereas PACU stay was also recorded to be significantly less in the Lamotrigine group patients compared to Topiramate $(\mathrm{p}<0.001)$ and control groups $(\mathrm{p}<$ 0.05 ; table 4 ).

\section{Discussion}

Pain is an important protective physiological response against an injury. However, numerous pathophysiological conditions such as diabetes, viral infections, nerve injury, and inflammation can give rise to persistent, chronic pain that is often refractory to currently available treatment options [17]. Following the painful peripheral stimulus, peripheral nociceptive neurons are activated and a train of action potentials is initiated and propagates along the axons of primary afferent nerve fibres to nerve terminals embedded in the dorsal horn of the spinal cord [18]. These nerve terminals release pro-nociceptive neurotransmitters such as glutamate, substance $\mathrm{P}$ and calcitonin gene-related peptide, 
Table 2. Effect on postoperative vital parameters (pulse, $\mathrm{BP}, \mathrm{MAP}, \mathrm{RR}$ and $\mathrm{SpO}_{2}$ ), mean $\pm \mathrm{SD}$

\begin{tabular}{|c|c|c|c|c|c|c|}
\hline \multirow{2}{*}{$\begin{array}{l}\text { Drugs group } \\
(\mathrm{n}=90)\end{array}$} & \multicolumn{6}{|c|}{ Time in hours } \\
\hline & baseline & 0 & 1 & 2 & 4 & 6 \\
\hline \multicolumn{7}{|c|}{ Control group (Diclofenac $100 \mathrm{mg}$ ) } \\
\hline Pulse & $72.9 \pm 1.4$ & $76.1 \pm 1.9$ & $74 \pm 1.7$ & $72.8 \pm 1.3$ & $72 \pm 1.1$ & $72.6 \pm 0.8$ \\
\hline SBP & $121.8 \pm 2.4$ & $126.7 \pm 2.6$ & $122.8 \pm 3.8$ & $121.5 \pm 1.8$ & $121.3 \pm 1.9$ & $121.4 \pm 1.9$ \\
\hline DBP & $81.4 \pm 1.9$ & $82.9 \pm 2.4$ & $82.8 \pm 0.9$ & $80.7 \pm 0.9$ & $80.7 \pm 0.9$ & $80.6 \pm 2$ \\
\hline MAP & $94.8 \pm 1.9$ & $97.3 \pm 2.5$ & $96.2 \pm 2.1$ & $94.3 \pm 1.3$ & $94.2 \pm 1.3$ & $94.2 \pm 1.3$ \\
\hline $\mathrm{RR}$ & $16 \pm 0.6$ & $18.6 \pm 1$ & $16.6 \pm 1$ & $16 \pm 0.8$ & $16 \pm 0.4$ & $16 \pm 0.6$ \\
\hline $\mathrm{SpO}_{2}$ & $99 \pm 0.6$ & $96 \pm 1$ & $98 \pm 0.5$ & $99 \pm 0.4$ & $99 \pm 0.3$ & $99 \pm 0.4$ \\
\hline \multicolumn{7}{|c|}{ Test group 1 (Topiramate $200 \mathrm{mg}$ ) } \\
\hline Pulse & $72.9 \pm 1$ & $75.9 \pm 1.9$ & $73.7 \pm 1.9$ & $72.9 \pm 1$ & $72 \pm 0.8$ & $72.9 \pm 1$ \\
\hline SBP & $121.8 \pm 2$ & $126.7 \pm 3$ & $123.6 \pm 4$ & $121.8 \pm 2$ & $121.8 \pm 2$ & $121.8 \pm 2$ \\
\hline DBP & $81.8 \pm 2$ & $83.8 \pm 2$ & $84 \pm 0.3$ & $80.9 \pm 1$ & $80.9 \pm 1$ & $80.9 \pm 1$ \\
\hline MAP & $95.1 \pm 2$ & $97.4 \pm 1.3$ & $97.2 \pm 1.3$ & $94.5 \pm 1.3$ & $94.5 \pm 1.3$ & $94.5 \pm 1.3$ \\
\hline $\mathrm{RR}$ & $16 \pm 0.4$ & $18.9 \pm 1$ & $16.9 \pm 1$ & $16 \pm 0.8$ & $16 \pm 0.6$ & $16 \pm 0.7$ \\
\hline $\mathrm{SpO}_{2}$ & $99 \pm 0.7$ & $97 \pm 1$ & $98 \pm 0.4$ & $99 \pm 0.5$ & $99 \pm 0.8$ & $99 \pm 0.3$ \\
\hline \multicolumn{7}{|c|}{ Test group 2 (Lamotrigine $100 \mathrm{mg}$ ) } \\
\hline Pulse & $75.4 \pm 3.2$ & $76.7 \pm 1.7$ & $74.5 \pm 1.5$ & $73.6 \pm 2$ & $73 \pm 1.8$ & $72.5 \pm 1$ \\
\hline SBP & $125.4 \pm 4.8$ & $128.5 \pm 2.7$ & $125.4 \pm 5.2$ & $124.7 \pm 4.8$ & $124.7 \pm 4.8$ & $124.7 \pm 4.8$ \\
\hline DBP & $80 \pm 0.8$ & $80.1 \pm 1.5$ & $81.5 \pm 2$ & $80 \pm 0.6$ & $80 \pm 0.4$ & $80 \pm 0.8$ \\
\hline MAP & $95.1 \pm 1.6$ & $96.2 \pm 1.47$ & $96.1 \pm 0.9$ & $94.9 \pm 1.6$ & $94.9 \pm 1.6$ & $94.9 \pm 0.4$ \\
\hline $\mathrm{RR}$ & $16 \pm 0.4$ & $18 \pm 0.8$ & $15.2 \pm 1$ & $16 \pm 0.6$ & $16 \pm 0.4$ & $16 \pm 0.3$ \\
\hline $\mathrm{SpO}_{2}$ & $99 \pm 0.4$ & $96.4 \pm 0.8$ & $98.2 \pm 0.4$ & $99 \pm 0.4$ & $99 \pm 0.3$ & $99 \pm 0.4$ \\
\hline
\end{tabular}

$\mathrm{SBP}=$ Systolic blood pressure $\mathrm{DBP}=$ diastolic blood pressure; $\mathrm{MAP}=$ mean arterial pressure $\mathrm{RR}=$ respiratory rate.

Table 3. Effect on postoperative VAS, facial, and behavioural pain scale score, mean \pm SD

\begin{tabular}{|c|c|c|c|c|c|c|}
\hline \multirow{2}{*}{$\begin{array}{l}\text { Drugs group } \\
(\mathrm{n}=90)\end{array}$} & \multicolumn{6}{|c|}{ Time in hours } \\
\hline & 0 & 1 & 2 & 4 & 6 & 24 \\
\hline \multicolumn{7}{|c|}{ Control group (Diclofenac $100 \mathrm{mg}$ ) } \\
\hline VAS & $2.3 \pm 0.5$ & $3.4 \pm 0.4$ & $4.7 \pm 0.6$ & $4.3 \pm 0.9$ & $4 \pm 0.3$ & $2.3 \pm 0.4$ \\
\hline FRS & $2.3 \pm 0.5$ & $3.6 \pm 0.5$ & $4.3 \pm 0.3$ & $3.7 \pm 0.4$ & $4 \pm 0.4$ & $2.3 \pm 0.5$ \\
\hline BRS & $2.3 \pm 0.5$ & $3.2 \pm 0.4$ & $4.2 \pm 0.5$ & $3.1 \pm 0.3$ & $4 \pm 0.3$ & $2.3 \pm 0.4$ \\
\hline ADRs & Nausea $=4$ & Vomiting $=13$ & & & & \\
\hline \multicolumn{7}{|c|}{ Test group 1 (Topiramate $200 \mathrm{mg}$ ) } \\
\hline VAS & $2.5 \pm 0.5$ & $3.9 \pm 0.5^{*, \dagger}$ & $4.8 \pm 0.3^{\dagger}$ & $4.0 \pm 0.2$ & $4 \pm 0.4$ & $2.5 \pm 0.4$ \\
\hline FRS & $2.5 \pm 0.5$ & $3.8 \pm 0.5^{\dagger}$ & $4.6 \pm 0.5^{\dagger}$ & $3.5 \pm 0.3$ & $4 \pm 0.5$ & $2.5 \pm 0.5$ \\
\hline BRS & $2.5 \pm 0.5$ & $3.7 \pm 0.5^{*, \dagger}$ & $4.5 \pm 0.5^{\dagger}$ & $3 \pm 0.2$ & $4 \pm 0.2$ & $2.5 \pm 0.5$ \\
\hline ADRs & Nausea $=8$ & Vomiting $=18$ & & & & \\
\hline \multicolumn{7}{|c|}{ Test group 2 (Lamotrigine $100 \mathrm{mg}$ ) } \\
\hline VAS & $2 \pm 0.3$ & $3 \pm 0.3^{*}$ & $4.1 \pm 0.4^{*}$ & $4 \pm 0.2$ & $3.3 \pm 0.6$ & $2 \pm 0.1$ \\
\hline FRS & $2 \pm 0.2$ & $3.2 \pm 0.5^{*}$ & $4 \pm 0.2$ & $4 \pm 0.4$ & $3.2 \pm 0.4$ & $2 \pm 0.2$ \\
\hline BRS & $2 \pm 0.2$ & $3.2 \pm 0.5$ & $4.1 \pm 0.4$ & $3.8 \pm 0.4$ & $3.2 \pm 0.4$ & $2 \pm 0.2$ \\
\hline ADRs & Nausea $=2$ & Vomiting $=8$ & & & & \\
\hline
\end{tabular}

${ }^{*} \mathrm{p}<0.05$ compared to control. ${ }^{\dagger} \mathrm{p}<0.05$ compared to Lamotrigine.

$\mathrm{ADR}=$ Adverse drug reaction. 
Table 4. Postoperative rescue analgesic requirement and PACU stay in study subjects

\begin{tabular}{|c|c|c|c|}
\hline Drug group $(\mathrm{n}=90)$ & $\begin{array}{l}\text { Analgesic needed in } \\
24 \mathrm{~h} \text { (Diclofenac), mg }\end{array}$ & $\begin{array}{l}\text { Per patient requirement, } \\
\text { median (IQR) }\end{array}$ & $\begin{array}{l}\text { PACU stay, min, } \\
\text { mean } \pm S D\end{array}$ \\
\hline Control group (Diclofenac 100 mg) & 5,200 & $150(150-200)$ & $51 \pm 13.9$ \\
\hline Test group 1 (Topiramate $200 \mathrm{mg}$ ) & 5,400 & $200(150-200)$ & $56.5 \pm 3.2^{\dagger}$ \\
\hline \multirow[t]{3}{*}{ Test group 2 (Lamotrigine $100 \mathrm{mg}$ ) } & 3,350 & $100(100-100)^{\dagger, *}$ & $40.6 \pm 11.7^{\dagger, * *}$ \\
\hline & \multicolumn{3}{|c|}{ Time of rescue analgesic administration, $\mathrm{mg}$} \\
\hline & $0-4 \mathrm{~h}$ & $4-12 \mathrm{~h}$ & $12-24 \mathrm{~h}$ \\
\hline Control group (Diclofenac 100 mg) & 1,050 & 1,950 & 2,200 \\
\hline Test group 1 (Topiramate $200 \mathrm{mg}$ ) & 1,500 & 1,850 & 2,350 \\
\hline Test group 2 (Lamotrigine $100 \mathrm{mg}$ ) & 0 & 1,400 & 1,950 \\
\hline \multicolumn{4}{|c|}{$\begin{array}{l}\text { IQR }=\text { Interquartile range. } \\
{ }^{\dagger} \mathrm{p}<0.05 \text { compared to control. } \\
* \mathrm{p}<0.05 \text { compared to Topiramate. } \\
* * \mathrm{p}<0.01 \text { compared to Topiramate. } \\
\mathrm{p} \text { values by Mann-Whitney U test for per patient analgesic requirement and Student's t test for PACU stay. }\end{array}$} \\
\hline
\end{tabular}

which then activate postsynaptic receptors on neurons of the spinothalamic tract. These nerve projections to the thalamus allow the pain perception [18]. Descending pathways from the cortex to the spinal cord modulate pain responses [17]. The propagation, processing of pain signals, and initial action potential generation are dependent on, and modulated by, a congregation of different ion channels and receptors, among these specifically, voltage gated sodium channels (VGSCs) [19] and T-type voltage gated calcium channels (VGCCs); expressed in cell bodies and nerve endings of afferent fibres contribute to the regulation of neuronal excitability by the initiation of action potential trains. They can lower the threshold for action potentials, promote bursting activity and synaptic excitation, and all actions that favor the development of enhanced pain. On the contrary, N-type VGCCs are highly expressed at presynaptic nerve terminals where they open in response to incoming action potentials and mediate calcium entry into the synapse. This in turn triggers synaptic vesicle release and the activation of spinothalamic neurons. Furthermore, N-type VGCCs are a key target for the inhibition by opioid receptor pathways and descending norepinephrine activation of adrenergic pathways. Interestingly, other VGCC subtypes do not appear to play a major role in pain signaling in primary afferent fibres [20]. As a result, VGSCs, N-type and T-type VGCCs are considered prime targets for the development of novel analgesics (fig. 3).

Study of Novel Antiepileptic Agents Lamotrigine and Topiramate in Patients
Pre-emptive analgesia is a treatment that is initiated before the surgical procedure to 'pre-empt' or prevent neurophysiological and biochemical consequences of a noxious input to the CNS provoked by the procedure [4]. It means the concept of pre-emptive analgesia is not to prevent pain but to prevent CNS alterations leading to pain amplification following first pain experience and development of chronic pain syndromes [21]. Considering this 'protective' effect on the nociceptive pathways, preemptive analgesia has the potential to be more effective than a similar analgesic treatment initiated after surgery. Consequently, immediate postoperative pain may be reduced and the development of chronic pain may be prevented [22].

Diclofenac sodium is an established pre-emptive analgesic with extensively studied pre-emptive analgesic efficacy in earlier studies $[6,7,23]$. In this study, pre-emptive analgesic efficacy of Lamotrigine and Topiramate was studied and compared with Diclofenac sodium. Results of this study are strongly suggestive of pre-emptive analgesic efficacy of Lamotrigine but not the Topiramate; as patients were more comfortable throughout the study, which is evident from significantly lesser pain score, PACU stay, and postoperative analgesic requirement in Lamotrigine-treated group. These results are in agreement with few clinical studies that mention novel antiepileptic like Gabapentin impart pre-emptive analgesic effect [8-10]. However, we could not come across any study with Lamotrigine and Topiramate pre-emptive an- 
Fig. 3. Role of VGSCs and VGCCs in the primary afferent pain signaling pathway.

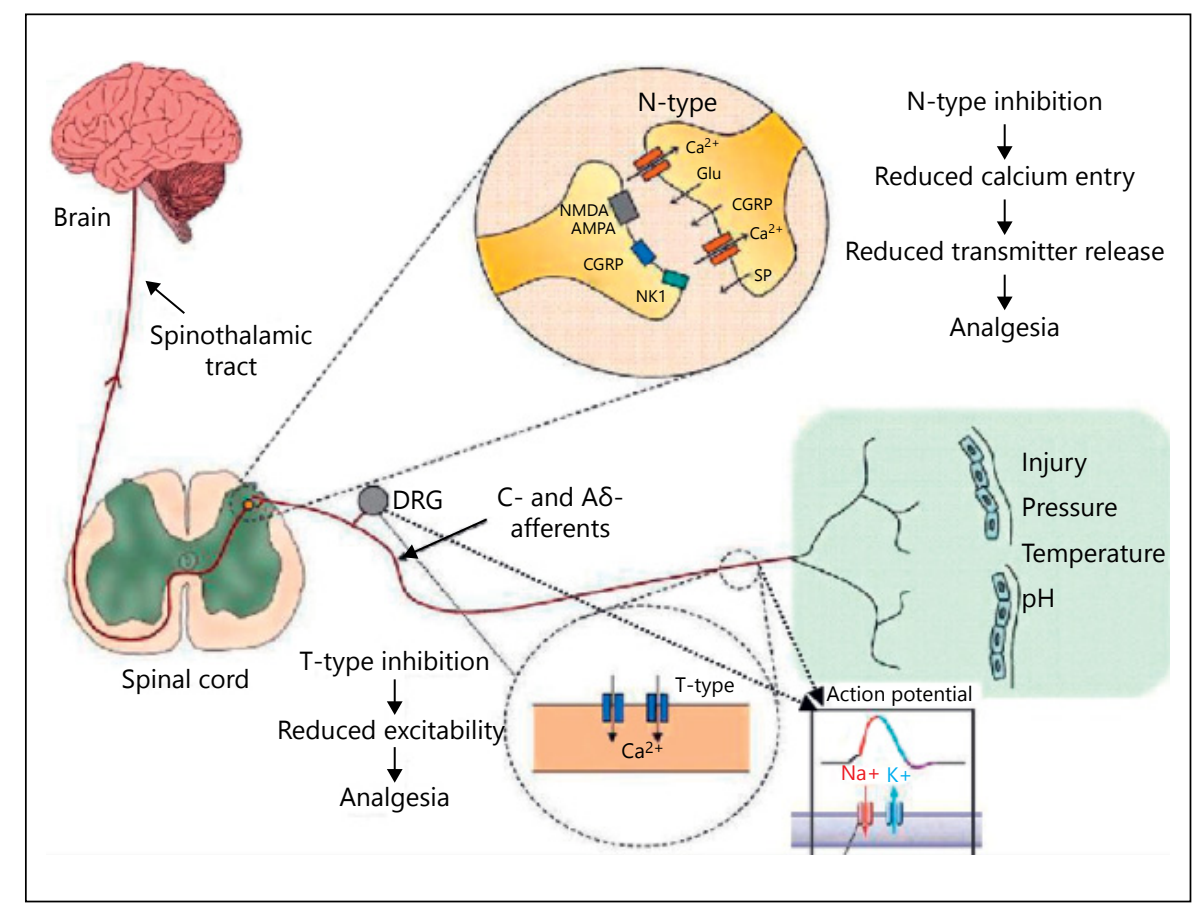

algesia. Hence, results of this study may be a fruitful accumulation in the data favoring use of novel antiepileptics for pre-emptive analgesia.

Postoperative pain is mostly nociceptive, involves neurophysio-chemical chain of events that cause neurotransmitter release such as glutamate and aspartate present in dorsal horn laminae. They bind and activate amino-3-hydroxyl-5-methyl-4-proprionic acid (AMPA) and kainate receptors (KARs) that regulate $\mathrm{Na}+$ and $\mathrm{K}+$ ion influx. Activated AMPA and KAR receptors, cause priming of NMDA receptors, which is voltage sensitive and glutamate, aspartate gated. AMPA-induced membrane depolarization dislodges a magnesium plug from the ion channel of the NMDA receptor, causing entry and accumulation of calcium ions into the spinal neuron and leading to the rapid impulse transmission and independent firing [24]. Topiramate acts by a complex mechanism of action involving inhibition of sodium and calcium channels, increasing the activity of chloride channels in neurons, thus reducing the excitability of neuronal circuits by inhibiting synaptic neurotransmitters release, which in turn cause inhibition of AMPA-induced NMDA receptor sensitization and hence inhibition of spinal and supraspinal sensitization [25]. Peripheral antinociceptive effect of Topiramate is observed at low doses; however, for spinal and supraspinal effects higher doses need to be given. In this study, we used a single low dose of
Topiramate. Lack of pre-emptive analgesic efficacy of Topiramate observed may be due to an inadequate dose [26].

Lamotrigine belongs to the sodium channel blocking class of antiepileptic drugs [27]. It inhibits voltage-sensitive sodium channels and also blocks $\mathrm{N}$-type calcium channels, densely expressed in the superficial laminae (I, II) of the dorsal horn, the site of synapse for first-order primary afferent neurons [19]. It stabilizes the presynaptic neuronal membrane, thus preventing the release of excitatory neurotransmitters such as glutamate and inhibits sustained repetitive neuronal firing [11]. Lamotrigine has weak 5-hydroxytryptamine-3 (5-HT3) receptor inhibitory action as well [28]. Supraspinal 5 -HT3 receptors in spinal descending pronociceptive pathway play a role in nociception [29]. Lamotrigine-mediated blockade may also have contributed to its antinociceptive potential. Superior pre-emptive analgesic efficacy of Lamotrigine compared to Diclofenac and Topiramate can be explained on the basis of these multimodal actions.

The limitation of this study is that the pre-emptive analgesic efficacy was studied only in patients operated under spinal anesthesia; patients operated under general anesthesia were not included in the study. Furthermore, the pre-emptive analgesic efficacy of a single oral dose of newer antiepileptics was evaluated. The single highest 
safe dose of Lamotrigine needs to be evaluated to offer maximal postoperative pain control through practicing pre-emptive analgesia. To rule out pre-emptive analgesic efficacy of Topiramate, higher permissible doses need to be studied.

\section{Conclusions}

Novel antiepileptic Lamotrigine is strongly recommended to prevent CNS sensitization leading to pain amplification by the incisional and inflammatory injuries occurring during surgery as became evident from results. However, Topiramate, though proved to be effective in neuropathic pain was found to be ineffective in pre-emptive analgesic efficacy. To strengthen our findings and to evaluate the diverse pre-emptive mechanisms of newer antiepileptics, more studies need to be carried out.

\section{Acknowledgement}

The authors are thankful to Dr. A.V. Bhore, Dean SKNMC and Dr. R.W. Naphade, HOD Anesthesia for providing facilities to carry out of the experiments.

\section{Author Contribution}

A.G. contributed in definition of intellectual content, literature search, clinical studies, data acquisition or analysis, manuscript preparation, editing, review and Guarantor. U.A.B. contributed in manuscript concept and design, literature search, clinical studies, data and statistical analysis and manuscript preparation. P.S. contributed in clinical studies and data acquisition. R.Y. contributed in definition of intellectual content and manuscript review. S.S. contributed in clinical studies and data acquisition.

\section{Disclosure Statement}

The authors have no conflict of interest.

\section{References}

1 Taleska G, Trajkovska T, Kokareva A, Popovska A, Naumoska M, Gavrilovska A, Dzhambazovska-Trajkovska V, Toleska M, Dimov A: Preemptive epidural analgesia with bupivacaine and sufentanyl and the effects of epiduraly added epinephrine for thoracic surgery. Macedonian J Med Sci 2010;3:46-53.

2 Dahl JB, Møiniche S: Pre-emptive analgesia. Br Med Bull 2004;71:13-27.

3 Woolf CJ, Shortland P, Coggeshall RE: Peripheral nerve injury triggers central sprouting of myelinated afferents. Nature 1992;355: 75-78.

4 Kissin I: Preemptive analgesia. Anesthesiology 2000;93:1138-1143.

5 Kashefi P, Honarmand A, Safavi M: Effects of preemptive analgesia with celecoxib or acetaminophen on postoperative pain relief following lower extremity orthopedic surgery. Adv Biomed Res 2012;1:66.

6 Canbay O, Karakas O, Celebi N, Peker L, Coskun F, Aypar U: The preemptive use of diclofenac sodium in combination with ketamine and remifentanil does not enhance postoperative analgesia after laparoscopic gynecological procedures. Saudi Med J 2006;27: 642-645.

7 Goel P, Kothari S, Gupta N, Kumar A, Chaturvedi SK: Pre emptive analgesia with iv paracetamol and iv diclofenac sodium in patients undergoing various surgical procedures: a comparative study. Int J Biol Med Res 2013;4:3294-3300.

8 Pandey CK, Priye S, Singh S, Singh U, Singh RB, Singh PK: Preemptive use of gabapentin significantly decreases postoperative pain and rescue analgesic requirements in laparoscopic cholecystectomy. Can J Anaesth 2004;51: 358-363.

9 Parikh HG, Dash SK, Upasani CB: Study of the effect of oral gabapentin used as preemptive analgesia to attenuate post-operative pain in patients undergoing abdominal surgery under general anesthesia. Saudi J Anaesth 2010;4:137-141.

10 Grover VK, Mathew PJ, Yaddanapudi S, Sehgal S: A single dose of preoperative gabapentin for pain reduction and requirement of morphine after total mastectomy and axillary dissection: randomized placebo-controlled double-blind trial. J Postgrad Med 2009;55: 257-260.

11 Paudel KR, Bhattacharya S, Rauniar G, Das $\mathrm{B}$ : Comparison of antinociceptive effect of the antiepileptic drug gabapentin to that of various dosage combinations of gabapentin with lamotrigine and topiramate in mice and rats. J Neurosci Rural Pract 2011;2:130136.

12 Vinik AI, Tuchman M, Safirstein B, Corder C, Kirby L, Wilks K, Quessy S, Blum D, Grainger J, White J, Silver M: Lamotrigine for treatment of pain associated with diabetic neuropathy: results of two randomized, doubleblind, placebo-controlled studies. Pain 2007; 128:169-179.

13 Panah Khahi M, Yaghooti AA, Marashi SH, Nadjafi A: Effect of pre-emptive gabapentin on postoperative pain following lower extremity orthopaedic surgery under spinal anaesthesia. Singapore Med J 2011;52:879882.
14 Cohen LL, Lemanek K, Blount RL, Dahlquist LM, Lim CS, Palermo TM, McKenna KD, Weiss KE: Evidence-based assessment of Pediatric Pain. J Pediatr Psychol 2008;33:939955.

15 Khoromi S, Patsalides A, Parada S, Salehi V, Meegan JM, Max MB: Topiramate in chronic lumbar radicular pain. J Pain 2005;6:829-836.

16 Cohen LB, Delegge MH, Aisenberg J, Brill JV, Inadomi JM, Kochman ML, Piorkowski JD Jr: AGA Institute review of endoscopic sedation. Gastroenterology 2007;133:675-701.

17 Porreca F, Ossipov MH, Gebhart GF: Chronic pain and medullary descending facilitation. Trends Neurosci 2002;25:319-325.

18 Krarup C: An update on electrophysiological studies in neuropathy. Curr Opin Neurol 2003;16:603-612.

19 Markman JD, Dworkin RH: Ion channel targets and treatment efficacy in neuropathic pain. J Pain 2006; 7(1 suppl 1):S38-S47.

20 Zamponi GW, Lewis RJ, Todorovic SM, Arneric SP, Snutch TP: Role of voltage-gated calcium channels in ascending pain pathways. Brain Res Rev 2009;60:84-89.

21 Werner MU, et al: Does an acute pain service improve postoperative outcome? Anesth Analg 2002;95:1361-1372.

22 Woolf CJ, Chong MS: Preemptive analgesiatreating postoperative pain by preventing the establishment of central sensitization. Anesth Analg 1993;77:362-379.

23 Campbell WI, Kendrick R, Patterson C: Intravenous diclofenac sodium. Does its administration before operation suppress postoperative pain? Anaesthesia 1990;45:763-766. 
24 Ji R, Kohno T, Moore KA, Woolf C: Central sensitization and LTP: do pain and memory share similar mechanisms? Trends Neurosci 2003;26:696-705.

25 Shank, RP, Maryanoff BE: Molecular pharmacodynamics, clinical therapeutics, and pharmacokinetics of topiramate. CNS Neurosci Ther 2008;14:120-142.
26 Rus NN, Bocşan C, Vesa ŞC, Coadă CA, Buzoianu AD: Topiramate in nociceptive pain experimental analgesia study. HVM Bioflux 2013;5:70-76.

27 Rogawski M: Chapter 1: principles of antiepileptic drug action; in Levy RH, Mattson $\mathrm{RH}$ Meldrum BS, Perucca E (eds): Antiepileptic Drugs, ed 5. Lippincott Williams \& Wilkins, 2002, pp 3-22.

28 Thomas SP, Nandhra HS, Jayaraman A: Systematic review of lamotrigine augmentation of treatment resistant unipolar depression (TRD). J Ment Health 2010;19:168-175.
29 Bhosale UA, Khobragade R, Naik C, Yegnanarayan R, Kale J: Randomized, doubleblind, placebo-controlled study to investigate the pharmacodynamic interaction of 5-HT3 antagonist ondansetron and paracetamol in postoperative patients operated in an ENT department under local anesthesia. J Basic Clin Physiol Pharmacol 2015;26:217-222. 